\title{
Photoproducts Formation from Salicylic Acid and Poly(allylamine hydrochloride) in Aqueous Solution Induced by UV-B Radiation
}

\author{
Romario J. da Silva, Nara C. de Souza, and Josmary R. Silva \\ Grupo de Materiais Nanoestruturados, Universidade Federal de Mato Grosso, 78600-000 Barra do Garças, MT, Brazil \\ Correspondence should be addressed to Josmary R. Silva; josmarysilva@ufmt.br
}

Received 8 April 2015; Revised 29 July 2015; Accepted 2 August 2015

Academic Editor: Golam M. Bhuiyan

Copyright (C) 2015 Romario J. da Silva et al. This is an open access article distributed under the Creative Commons Attribution License, which permits unrestricted use, distribution, and reproduction in any medium, provided the original work is properly cited.

We report on the investigation of the influence of UV-B radiation $(306 \mathrm{~nm})$ on the salicylic acid mixed with poly(allylamine hydrochloride), $\mathrm{PAH}$, in aqueous solution. UV-Vis spectra versus irradiation time reveal kinetics of photoproducts formation. At pH 9 and 10 are found a growth regime and another of decay of photoproducts formation. In addition, the growth does not depend on temperature, whereas the decay showed a significant dependence on this parameter suggesting a thermally activated process. These processes were well fitted with first-order exponential functions.

\section{Introduction}

Exposition of drugs to ultraviolet (UV) radiation is a very important issue since this situation can lead to a loss of activity or even formation of harmful products from drugs. In general, this occurs as a result of phototransformation of drug molecules after absorbing UV radiation [1]. Consequently, the effectiveness of drugs relies on their behavior under exposition to UV radiation. A number of studies of the influence of UV light on drugs have been performed on solution of free drugs [2-5] or in complexed ones [5]. Apart from the studies of the pure drugs in solution, other researches have focused on encapsulated drugs by using polyelectrolytes $[6,7]$. In these systems, there are interactions between the two kinds of components. Thus, it becomes important to study also the behavior of drugs mixed with polyelectrolytes under exposure to ultraviolet light. As seen previously, several investigations of the influence of UV radiation on drugs have been performed; however no research has been exploring the effects of UV radiation on solutions consisting of drugs mixed with polyelectrolytes, in particular, salicylic acid (SA) and poly(allylamine hydrochloride), PAH. Salicylic acid is colorless crystalline organic compound used against inflammations, relief of arthritis, and headache pain.
In addition, their derivatives are also used to treat heart disease [8]. PAH is commonly employed as encapsulation material $[6,9]$.

In this paper, we report an investigation of the effect of UV-B irradiation on salicylic acid mixed with PAH polyelectrolyte in aqueous solution. Kinetics of photoproducts formation is revealed and the influence of $\mathrm{pH}$ value and temperature on this process is explored.

\section{Materials and Methods}

2.1. Compounds and Solutions. Salicylic acid (SA) was obtained from Mob Lab Co. with molecular weight of $138.12 \mathrm{~g} \mathrm{~mol}^{-1}$ (Figure 1). Aqueous solutions were prepared at a concentration of $0.0625 \mathrm{~g} / \mathrm{L}$. The $\mathrm{pH}$ values of the solutions were adjusted with ammonium hydroxide $(\mathrm{NH} 4 \mathrm{OH})$ $1 \mathrm{~mol} / \mathrm{L}$ for basic region $(6,9$, and 10$)$ and hydrochloric acid $(\mathrm{HCl}) 1 \mathrm{~mol} / \mathrm{L}$ of an acid solution of $\mathrm{pH} 2$. Poly(allylamine hydrochloride), $\mathrm{PAH}, \mathrm{MW} \sim 15000$, was commercially obtained from Sigma-Aldrich Co. and used as receipt. Aqueous solutions of the polyelectrolytes were prepared with the same concentrations and $\mathrm{pH}$ values of the solutions of SA. 
<smiles>O=C(O)c1ccccc1O</smiles>

FIgURE 1: Chemical structures of salicylic acid.

\subsection{Photoproducts Formation Induced by UV-B Light Irradia-} tion. The expositions of the solutions to ultraviolet radiation were carried out by placing the samples into a homemade chamber equipped with a UV-B lamp (Sankyo Denki G15T8E). This lamp has the emission range of $280-360 \mathrm{~nm}$ with a peak at $306 \mathrm{~nm}$, power consumption of $15.0 \mathrm{~W}$, and emission of UV-B of $3.0 \mathrm{~W}$. Solutions of SA + PAH with a concentration of $0.0625 \mathrm{~g} / \mathrm{L}$ and $\mathrm{pH} 9$ were prepared $(50: 50, \mathrm{v} / \mathrm{v})$. Then, aliquots of $10.0 \mathrm{~mL}$ were placed in a beaker and taken to the UV-B chamber (Figure 2), which was subjected to irradiation at a distance from the source (lamp) of $160.0 \mathrm{~mm}$. Along $12 \mathrm{~h}$, the irradiation process was interrupted at intervals of $1 \mathrm{~h}$ and a fraction of the solution was collected and had its UV-Vis absorption measured. After obtaining the spectrum, the solution was returned to the beaker. The schematic sequence of steps of the procedure is shown in Figure 2.

2.3. Influence of $p H$ Value. For the study of the influence of $\mathrm{pH}$, solutions of AS and $\mathrm{PAH}$ were prepared with equal volumes at three different $\mathrm{pH}$ values $(6,9$, and 10). Each system was then subjected to the procedure of Figure 2. It should be noted that the concentration of all solutions used in this study was $0.0625 \mathrm{~g} / \mathrm{L}$.

2.4. Temperature Influence. To investigate the influence of temperature on photoproducts formation, it was necessary to use a thermal bath Brand New Ethics, model 500-1D. Since this device has dimensions greater than the ultraviolet chamber, and its temperature control system only works with heating, it was necessary to perform some adjustments that are indicated in Figure 3. The temperature values used ranged from 0 to $60^{\circ} \mathrm{C}$. To avoid thermal shock of solution, a cuvette and a Pasteur pipette were used to withdraw samples, which were kept in a container in the bath, as can be seen in Figure 3. Furthermore, once we removed the sample, it was quickly taken to the spectrophotometer, measured and then discarded.

2.5. UV-Vis Spectroscopy Analysis. Electronic absorption spectra for all experiments were taken using a spectrophotometer (Thermolab, Genesis 10) at room temperature.

\section{Results and Discussion}

3.1. Photoproducts Formation Induced by UV-B Irradiation. In order to investigate the effect of UV-B irradiation on the $\mathrm{SA}+\mathrm{PAH}$ solution, we first examined the influence of the radiation on a solution with only SA $(0.0625 \mathrm{~g} / \mathrm{L} \mathrm{g} / \mathrm{mL}, \mathrm{pH}$ 9). Figure 4(a) illustrates the UV-Vis absorption spectra of
SA in aqueous solution at different times of UV-B irradiation $(306 \mathrm{~nm})$. All spectra present two bands with maximal absorption at 230 and $295 \mathrm{~nm}$. Both bands are assigned to $\pi-\pi^{*}$ electronic transitions either in carboxyl and aromatic heterocyclic $(230 \mathrm{~nm})$ or in phenolic hydroxyl oxygen and cyclobenzene $(295 \mathrm{~nm})$ [10]. Before and after the irradiation, there is no significant alteration of absorption peak position.

After the study of SA solution, we have examined the effect of UV-B irradiation on SA + PAH solution. Figure 4(b) depicts the absorption spectra of $\mathrm{SA}+\mathrm{PAH}$ in aqueous solution $(0.0625 \mathrm{~g} / \mathrm{L} \mathrm{g} / \mathrm{mL}, \mathrm{pH} 9,50: 50, \mathrm{v} / \mathrm{v})$ at different times of UV-B irradiation. Before irradiation, the spectra present only two bands with maximal absorption at 230 and $295 \mathrm{~nm}$, as showed in Figure 4(a). These bands are also attributed to $\pi-\pi^{*}$ transitions in disubstituted benzene, as discussed previously. After the irradiation, a novel band is formed ranging from 340 to $350 \mathrm{~nm}$. It should be noted that the UV-B irradiation of pure $\mathrm{PAH}$ in aqueous solution does not produce the observed band (data not shown). Furthermore, this band is not observed when the SA aqueous solution is irradiated (see Figure 4(a)). This band is observed only when PAH is mixed with SA.

A possible explication to this band is the formation of complexes from SA with PAH. Such complexes when irradiated lead to generation of novel products (photoproducts) associated with observed band. Photodegradation of SA can be ruled out because no absorption band ranging from 340 to $350 \mathrm{~nm}$ is observed after the UV-B irradiation of SA solution (see Figure 4(a)). Furthermore, photodegradation causes a decrease in absorption band, event which is not observed [11]. Then, the photoproducts arise only for the system consisting of SA mixed with PAH in aqueous solution. In experiments using the same irradiation times, we did not observe photoproducts formation for $\mathrm{PAH}$ in aqueous solution (data not shown) and in pure SA solution (Figure 4(a)).

3.2. Kinetics of Photoproducts Formation and Its Dependence on $\mathrm{pH}$ Value. The monitoring of the absorption peak at $345 \mathrm{~nm}$ from results of study of UV-Vis absorption spectra at different UV-B irradiation times (Figure 4(b)) for the SA + $\mathrm{PAH}$ solution leads to a kinetics of photoproducts formation. Figure 5 exhibits the behavior of kinetics of photoproducts formation (at $345 \mathrm{~nm}$ ) as a function of irradiation time for $\mathrm{SA}+\mathrm{PAH}$ solution at three different $\mathrm{pH}$ values. It is well known that the behavior of SA or PAH is susceptible to $\mathrm{pH}$ value $[12,13]$. Here, we observe that at $\mathrm{pH} 6$ the amount of photoproducts and its rate of formation kinetics increase with increasing $\mathrm{pH}$ value, whereas at $\mathrm{pH} 9$ and 10 there are a growth and next a decay. At $\mathrm{pH} 9$, the drop occurs around $7 \mathrm{~h}$ and at pH 10 it occurs after $3 \mathrm{~h}$. Therefore, it is clear from our results that $\mathrm{pH} 9$ and 10 reveal two different kinetics regimes: growth and decay of photoproducts formation.

The increase in the photoproducts amount and its kinetics rate can be explained by considering that $\mathrm{OH}$ ions with the energy absorbed by the irradiation are used in the deprotonation of carboxyl and phenol from a plot of SA; when it reached a critical concentration, groups are linked to other ones by electrostatic interaction $\mathrm{NH}^{+}$from $\mathrm{PAH}$, thus promoting the crosslinking of the polymer chains. Consequently, it leads to 


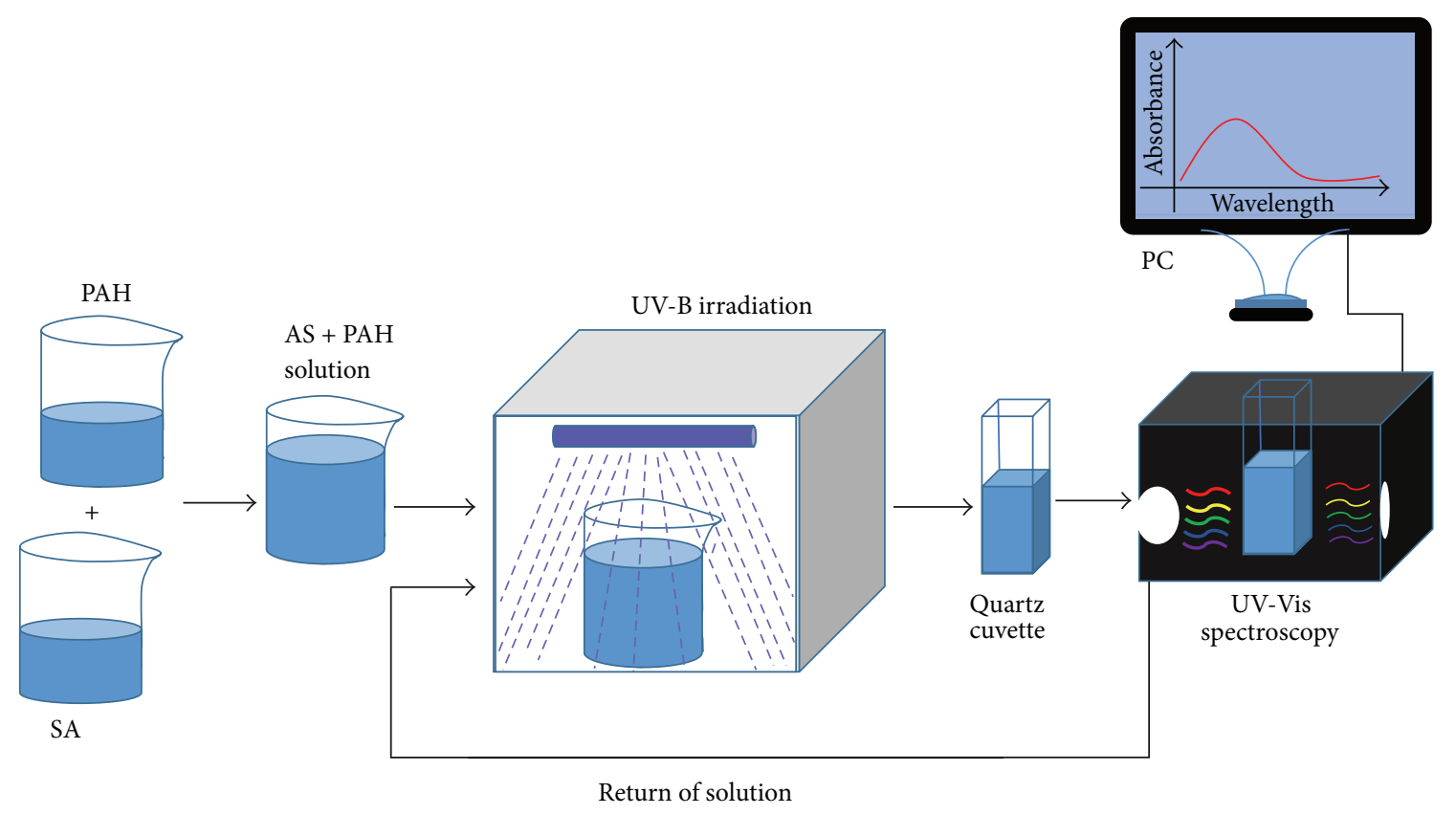

FIGURE 2: Schematic diagram of the irradiation procedure of SA + PAH solution.

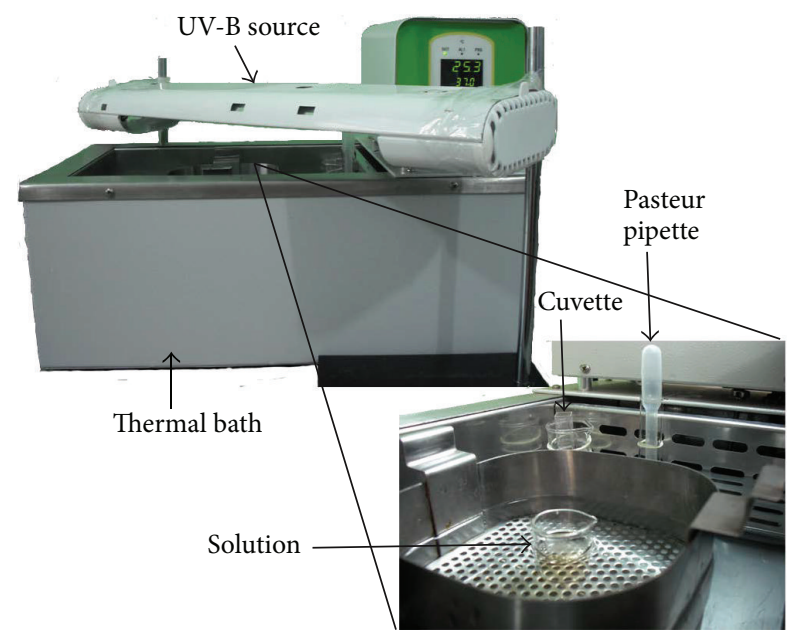

FIGURE 3: Experimental setup used to control the temperature of the solutions.

phase segregation observed. The occurrence of crosslinking triggered by electrostatic interactions between $\mathrm{PAH}$ and other molecules, which is accompanied by phase segregation, is reported in the literature [14].

A possible hypothesis for explaining the behavior of growth and decay of the kinetics of photoproducts formation is that while the solution is irradiated, photoproducts are formed until achieving a saturation amount. From this point, these species begin an aggregation which segregates the liquid phase and then forms cotton-shaped photoproducts, that is, a three-dimensional network of photoproducts (inset in Figure 4(b)). This kind of structure is opaque to the light beam of UV-Vis spectrophotometer.
3.3. Influence of Temperature on the Kinetics of Photoproducts Formation. In order to investigate the influence of temperature on the kinetics of photoproducts formation, we have performed an experiment in which the temperature of SA + PAH solution was changed from 5 to $60^{\circ} \mathrm{C}$ (see Section 2.4).

Figure 6 displays the absorbance kinetics, which is proportional to kinetics of photoproducts formation, as a function of the temperature $\left(5,25,40,50\right.$, and $\left.60^{\circ} \mathrm{C}\right)$ for the $\mathrm{SA}+\mathrm{PAH}$ solution $(0.062 \mathrm{~g} / \mathrm{L}, \mathrm{pH} 10,50: 50, \mathrm{v} / \mathrm{v})$ irradiated with $306 \mathrm{~nm}$ UV-B light $(15.0 \mathrm{~mW})$. It should be noted that each irradiation time is considered to be the time interval in which the solution was exposed to UV-B light as described in Section 2.4. The absorbance (at $345 \mathrm{~nm}$ ) without 

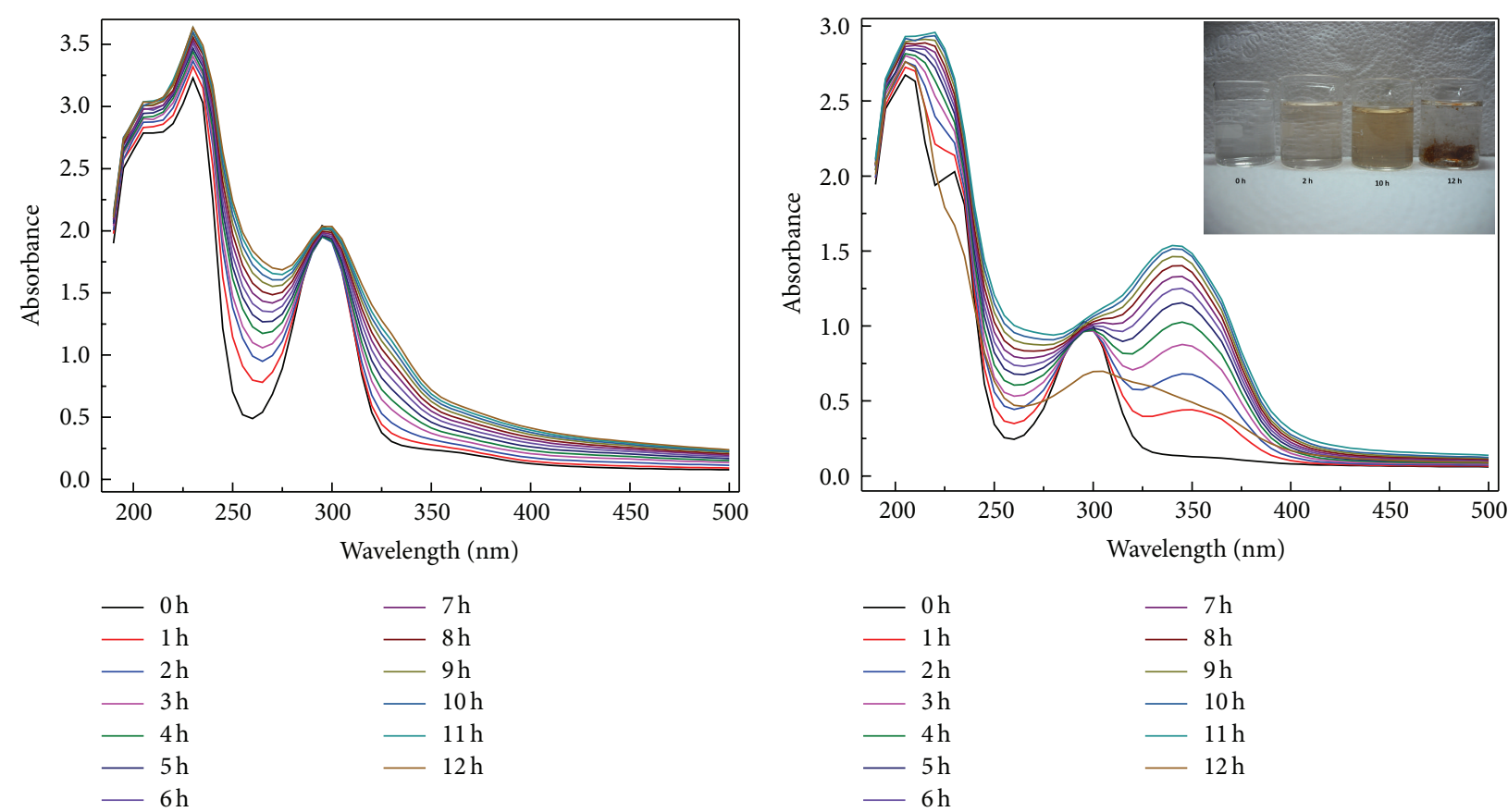

(a)

(b)

FIGURE 4: UV-Vis spectra for solutions of (a) pure SA and (b) SA + PAH at different irradiation times (0-12 h). Measurements performed at $\mathrm{pH} 9$ and $25^{\circ} \mathrm{C}$. The inset shows the image of the as-prepared SA + PAH solutions $(0 \mathrm{~h})$ and after UV-B irradiation $(2,10$, and $12 \mathrm{~h})$ at $25^{\circ} \mathrm{C}$, pH 10.

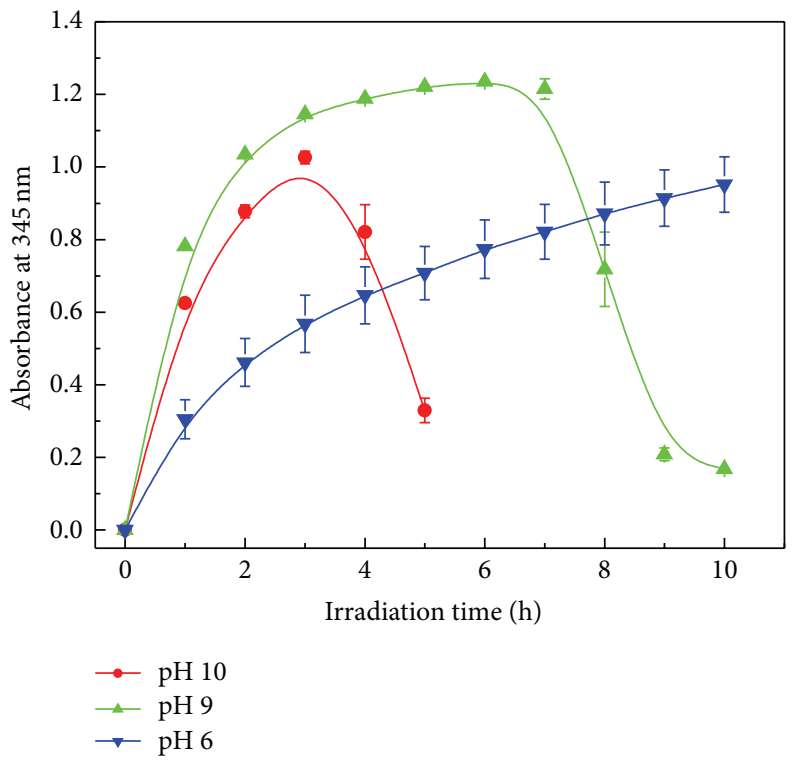

FIGURE 5: Kinetics of photoproducts formation monitored at $345 \mathrm{~nm}$ absorption peak at different pH values $(6,9$, and 10). Concentration of $0.0625 \mathrm{~g} / \mathrm{L}$ and temperature of $25^{\circ} \mathrm{C}$.

irradiation was considered as null reference. Solution at $\mathrm{pH}$ 10 was chosen for allowing the exploration of the process of growth and decay of kinetics of photoproducts formation. Furthermore, it provides a feasible range of time interval for the experiments.
For all temperatures, two kinetics regimes of photoproducts formation are observed. In the first, a growth until around $3-4 \mathrm{~h}$ is noted. Following that, there is a decay regime. The first regime is not affected by changing temperature, whereas the second reveals a significant variation of behavior. 


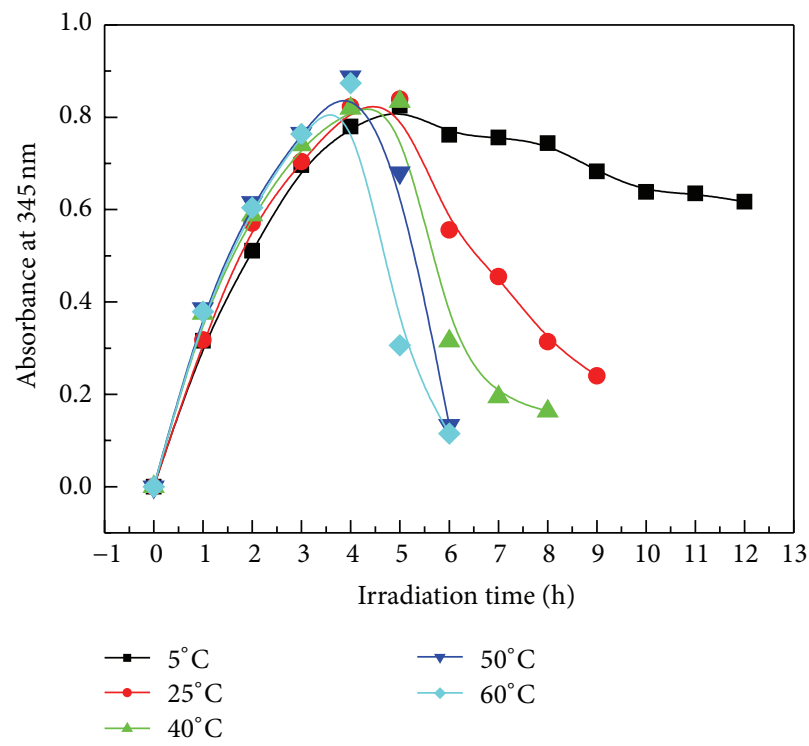

FIgURE 6: Absorbance at $345 \mathrm{~nm}$ as a function of irradiation time for SA + PAH solution (0.062 g/L, pH 10). UV-B irradiation (306 nm, $15.0 \mathrm{~mW}$ ).

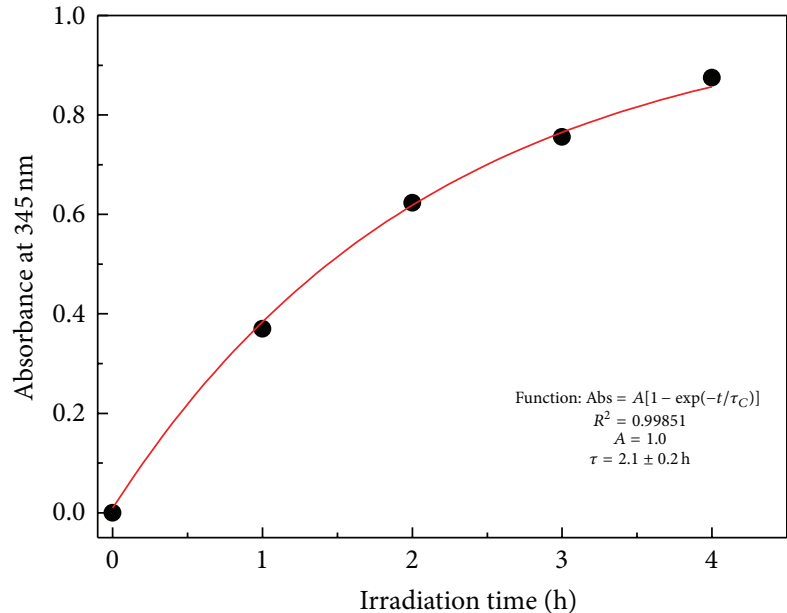

- $25^{\circ} \mathrm{C}$

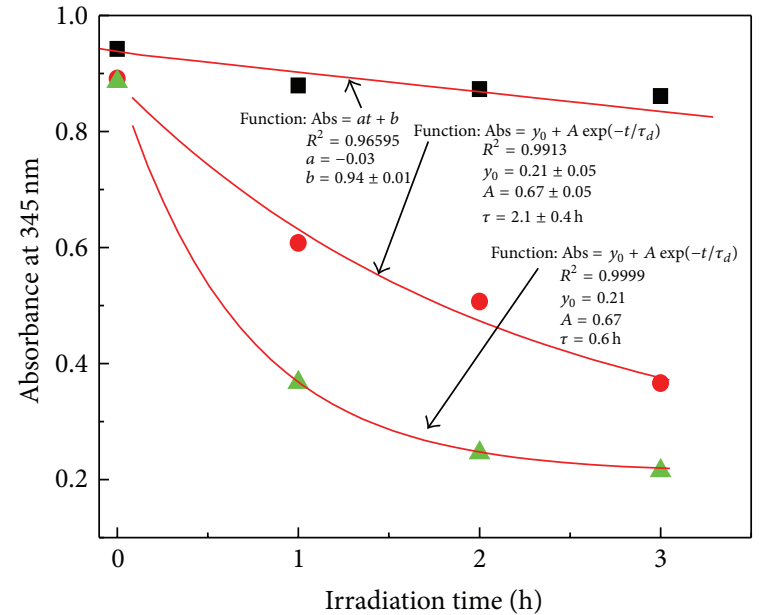

- $5^{\circ} \mathrm{C}$

- $25^{\circ} \mathrm{C}$

- $40^{\circ} \mathrm{C}$

(a)

(b)

Figure 7: (a) Growth kinetics regime of photoproducts formation for $25^{\circ} \mathrm{C}$ fitted by an exponential growth function. (b) Decay kinetics regime for 5,25 , and $40^{\circ} \mathrm{C}$ fitted by an exponential decay function.

The first regime is well fitted by the exponential growth function

$$
\mathrm{Abs}=A\left(1-e^{-t / \tau_{c}}\right)
$$

where Abs is the absorbance, $A$ is a constant, $t$ is the time, and $\tau_{c}$ is the time constant of growth. The independence of temperature observed in the first regime suggests that the photoproducts formation is not thermally activated.
The second regime is fitted by an exponential decay function as showed in Figure 7:

$$
\mathrm{Abs}=B e^{-t / \tau_{d}},
$$

where Abs is the absorbance, $B$ is a constant, $t$ is the time, and $\tau_{d}$ is the time constant of decay.

Figure 7 depicts only the decay kinetics regime at three different temperatures $\left(5,25\right.$, and $\left.40^{\circ} \mathrm{C}\right)$. At 25 and $40^{\circ} \mathrm{C}$, the decay is well fitted by an exponential decay function (2). 
However, at $5^{\circ} \mathrm{C}$, the decay is linear $(\mathrm{Abs}=a t+b)$ associated with slow segregation observed.

The kinetics behavior of photoproducts formation as a function of temperature can be explained as follows. When the temperature is increased, this causes an increase in diffusion rate of photoproducts in solution leading to an increase in its aggregation rate which, in turn, increases the rate of segregation. This would lead to phase segregation observed (inset of Figure 4(b)). It should be noted that we have tried to determine the apparent activation energy, but this was not possible because our results were irregular.

\section{Conclusion}

We have demonstrated that UV-B light irradiation on SA mixed with $\mathrm{PAH}$ in aqueous solution leads to kinetics of photoproducts formation. Solutions at $\mathrm{pH} 9$ and 10 reveal two different kinetics regimes, growth and decay. The growth rate does not depend on temperature, whereas the decay rate increases with increasing temperature leading to an increase in the rates of aggregation and phase segregation of photoproducts. These findings could be useful in developing capsules, which use drugs and polyelectrolytes that may suffer phototransformations when exposed to UV-B radiation from sunlight. Future works can be focused on determining composition of the photoproducts and studying this process using other UV radiation wavelengths.

\section{Conflict of Interests}

The authors declare that there is no conflict of interests regarding the publication of this paper.

\section{References}

[1] M. DellaGreca, M. R. Iesce, L. Previtera, M. Rubino, V. Barone, and O. Crescenzi, "Phototransformation of the drug trazodone in aqueous solution," Journal of Photochemistry and Photobiology A: Chemistry, vol. 199, no. 2-3, pp. 353-357, 2008.

[2] B. M. Rao, M. K. Srinivasu, K. P. Kumar et al., "A stability indicating LC method for rivastigmine hydrogen tartrate," Journal of Pharmaceutical and Biomedical Analysis, vol. 37, no. 1, pp. 57-63, 2005.

[3] M. DellaGreca, M. R. Iesce, M. Isidori, S. Montanaro, L. Previtera, and M. Rubino, "Phototransformation of amlodipine in aqueous solution: toxicity of the drug and its photoproduct on aquatic organisms," International Journal of Photoenergy, vol. 2007, Article ID 63459, 6 pages, 2007.

[4] F. Temussi, M. Passananti, L. Previtera et al., "Phototransformation of the drug rivastigmine: photoinduced cleavage of benzyl-nitrogen sigma bond," Journal of Photochemistry and Photobiology A: Chemistry, vol. 239, pp. 1-6, 2012.

[5] J. Smitka, A. Lemos, M. Porel et al., "Phototransformation of benzimidazole and thiabendazole inside cucurbit[8]uril," Photochemical and Photobiological Sciences, vol. 13, no. 2, pp. 310-315, 2014.

[6] R. Luo, S. S. Venkatraman, and B. Neu, "Layer-by-layer polyelectrolyte-polyester hybrid microcapsules for encapsulation and delivery of hydrophobic drugs," Biomacromolecules, vol. 14, no. 7, pp. 2262-2271, 2013.
[7] Q. Yi and G. B. Sukhorukov, "Single-component diazo-resin microcapsules for encapsulation and triggered release of small molecules," Particle and Particle Systems Characterization, vol. 30, no. 11, pp. 989-995, 2013.

[8] K. D. Rainsford, Aspirin and the Salicyclates, Butterworth, London, UK, 1984.

[9] Z. Wang, Y. Xie, and C. Gao, "Repeated protrusion of fluorescent pyrene nanorods on the surface of crosslinked poly(allylamine hydrochloride) microcapsules," RSC Advances, vol. 2, no. 30, pp. 11354-11358, 2012.

[10] L. A. Belyakova, A. M. Varvarin, D. Y. Lyashenko, O. V. Khora, and E. I. Oranskaya, "Complexation in a $\beta$-cyclodextrinsalicylic acid system," Colloid Journal, vol. 69, no. 5, pp. 546-551, 2007.

[11] M. Tian, B. Adams, J. Wen, R. Matthew Asmussen, and A. Chen, "Photoelectrochemical oxidation of salicylic acid and salicylaldehyde on titanium dioxide nanotube arrays," Electrochimica Acta, vol. 54, no. 14, pp. 3799-3805, 2009.

[12] S. Anandhakumar, V. Nagaraja, and A. M. Raichur, "Reversible polyelectrolyte capsules as carriers for protein delivery," Colloids and Surfaces B: Biointerfaces, vol. 78, no. 2, pp. 266-274, 2010.

[13] N. Peng, X. Xia, W. He, W. Liu, S. Huang, and R. Zhuo, "Fabrication and stability of porous poly(allylamine) hydrochloride (PAH)/poly(acrylic acid) (PAA) multilayered films via a cleavable-polycation template," Polymer, vol. 52, no. 5, pp. 12561262, 2011.

[14] K. Yoshida, R. Hashide, T. Ishii, S. Takahashi, K. Sato, and J.I. Anzai, "Layer-by-layer films composed of poly(allylamine) and insulin for $\mathrm{pH}$-triggered release of insulin," Colloids and Surfaces B: Biointerfaces, vol. 91, no. 1, pp. 274-279, 2012. 

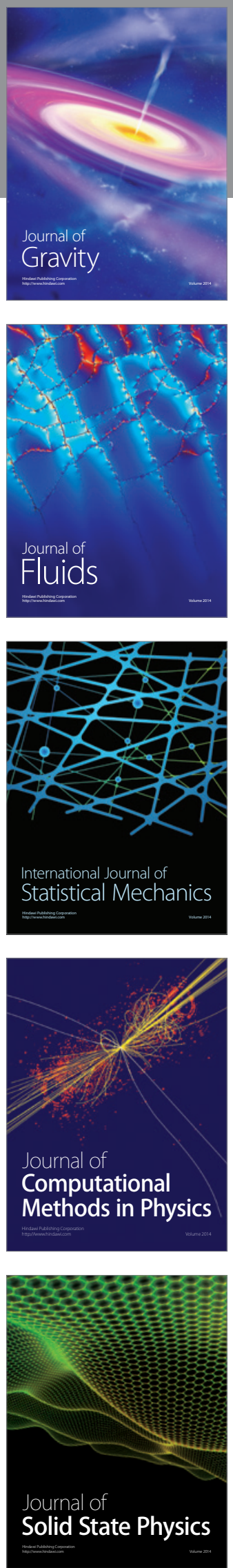

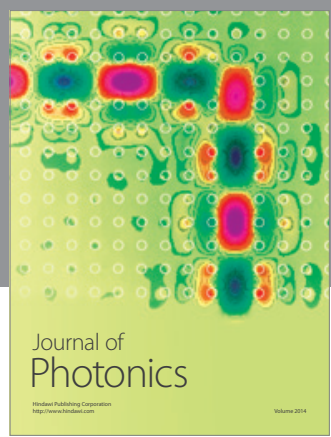

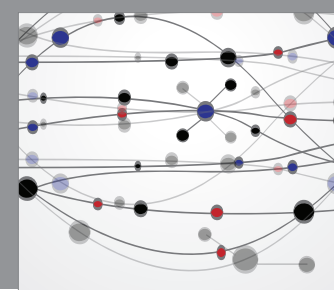

The Scientific World Journal

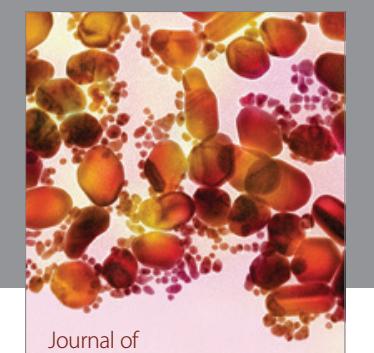

Soft Matter
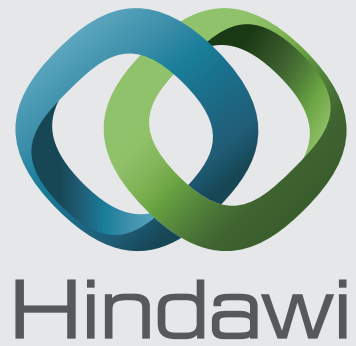

Submit your manuscripts at

http://www.hindawi.com
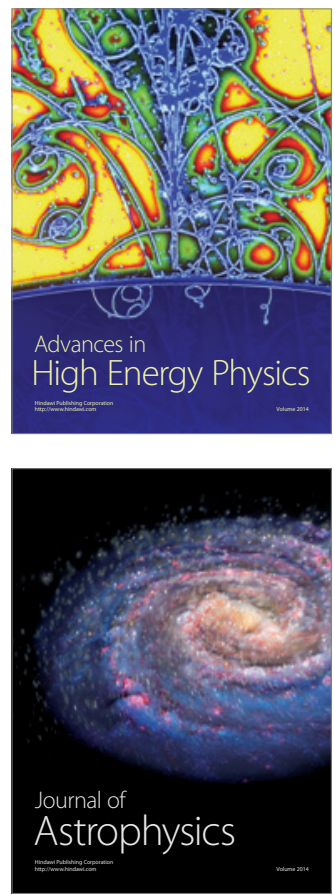
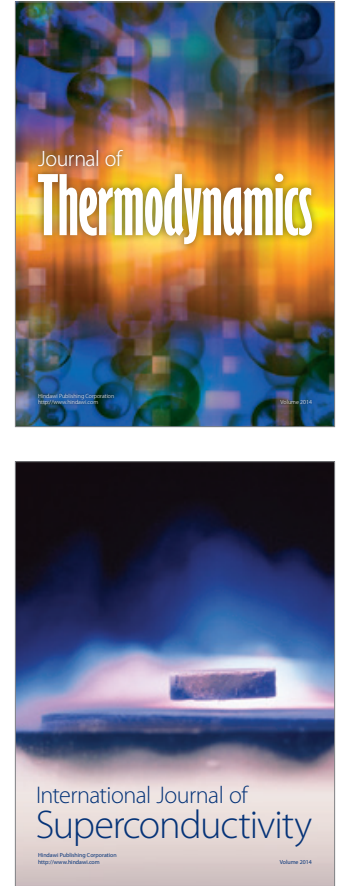
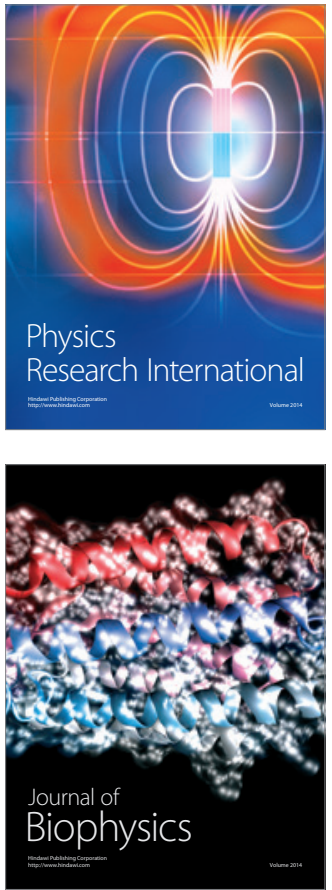
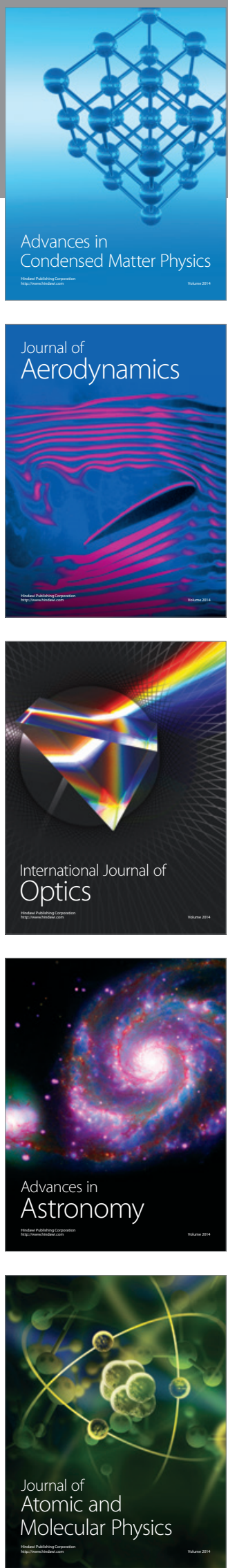